\title{
Patent Ductus Arteriosus, Hypotension, and Fluid Bolus in a Preterm Infant
}

\author{
Hilary A. Smith, Shabih Manzar*, MD
}

Department of Pediatrics School of Medicine Louisiana State University Health Sciences Center 1501 Kings Highway Shreveport, LA 71103

*Corresponding author: Shabih Manzar, Department of Pediatrics School of Medicine Louisiana State University Health Sciences Center 1501 Kings Highway Shreveport, LA 71103.

Received date: July 28, 2020; Accepted date: August 07, 2020; Published date: August 14, 2020

Citation: Smith, HA., Manzar S., (2020) Patent Ductus Arteriosus, Hypotension, and Fluid Bolus in a Preterm Infant. J, Clinical Cardiology and Cardiovascular Interventions, 3(7); Doi:10.31579/2641-0419/074

Copyright: () 2020 Shabih Manzar, This is an open access article distributed under the Creative Commons Attribution License, which permits unrestricted use, distribution, and reproduction in any medium, provided the original work is properly cited.

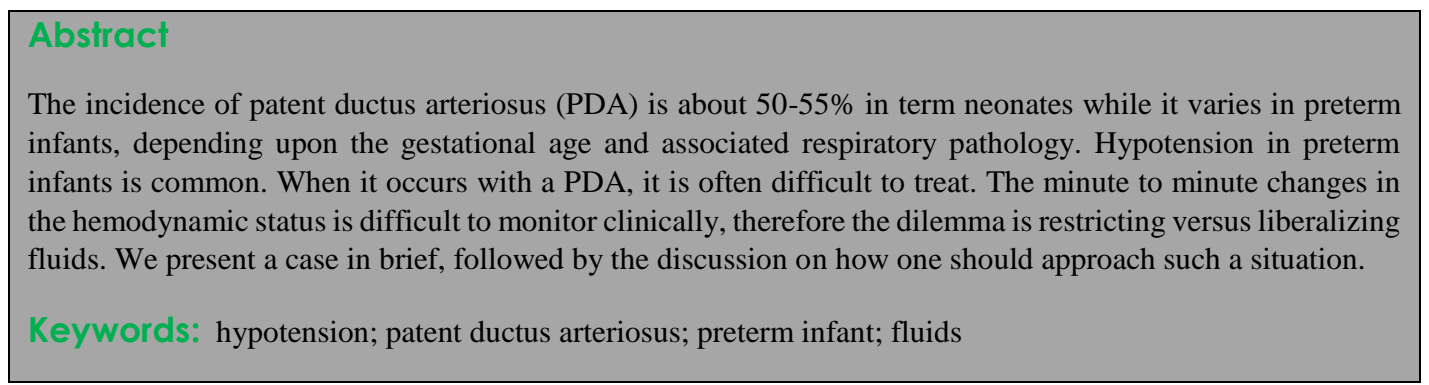

\section{Case}

This male infant was born at $26^{5 / 7}$ weeks of gestation to a 29 -year-old G2P0010 mother. The pregnancy was complicated by class B diabetes, omphalocele, and a two-vessel cord. Antenatal screen was negative for any chromosomal abnormalities (FISH and microarray negative). Mother received cerclage for short cervix. She presented to the labor unit complaining of leaking fluid. She received antibiotics, steroids, and magnesium sulphate. On examination the following day, the fetal heel was found to be protruding from the cervix. Mother was taken for cesarean section due to fetal malpresentation and omphalocele.

At delivery, the infant was immediately intubated and omphalocele was covered with sterile gauze. He was dried, stimulated, and bulb suctioned. Apgar scores were two and five at one and five minutes, respectively. Upon arrival to the NICU, he was placed on the high frequency oscillator ventilator. On day four of life, he developed a loud murmur and was noted to have low blood pressures. Echocardiogram showed mildly decreased left ventricular (LV) systolic function with ejection fraction $(\mathrm{EF})$ of $50-55 \%$, a small to moderate patent ductus arteriosus (PDA) with left to right shunt (peak gradient across shunt $<10$ $\mathrm{mmHg}$ ), and a patent forman ovale (PFO) versus a small secundum atrial septal defect (ASD) with left to right shunt. Hypotension management was started.

\section{Discussion:}

It has been estimated that the incidence of patent ductus arteriosus (PDA) in term infant is about 55\% in first 24 hours and 57 per 100000 live births after the second week of life. [1,2] In preterm infants the incidence is dependent upon the gestational age and associated respiratory pathology. It is estimated that about $55 \%$ of infants who weigh $<1000$ g would have a symptomatic PDA. [3] Medical and surgical management of a hemodynamically stable PDA in neonates remains controversial. Failure of ductal closure has been associated with increase in bronchopulmonary dysplasia and increase mortality. [4,5] Furthermore, management of concomitant hypotension is a clinical challenge. The usual trend among clinicians is to give a fluid bolus for hypotension. However, with a PDA, this might be detrimental.

Hypotension is difficult to define in preterm infants. A wide variation in normal ranges has been described. [6] The use of gestational age as a measure of mean blood pressure is discouraged. ${ }^{7}$ The indication for fluid rescue in hypotensive preterm infant lies in the complete clinical assessment. [8] What is the respiratory status (e.g. requiring persistent mechanical support)? Are there any signs of heart failure? Is there a large left-to-right ductus shunt with evidence of hemodynamic compromise on echocardiogram? Are there any signs of ductal steal phenomenon whereby descending aortic blood flow is compromised? Is there any oliguria or rising serum creatinine concentration?

As noted in (figure 1), there were no definite signs of severe pulmonary overload in this infant. The chest x-ray showed right upper lobe atelectasis and pulmonary interstitial emphysema without significant haziness. However, (Figure 2a) demonstrates a significant PDA with leftto-right shunt and (Figure 2b) shows a dilated left atrium suggesting pulmonary overflow. In the same picture (Figure 2c), however, a low left ventricular diastolic volume is noted. In summary, with the mixed echocardiographic findings, one cannot make a concrete decision regarding the need for a fluid bolus. 
Figure 1

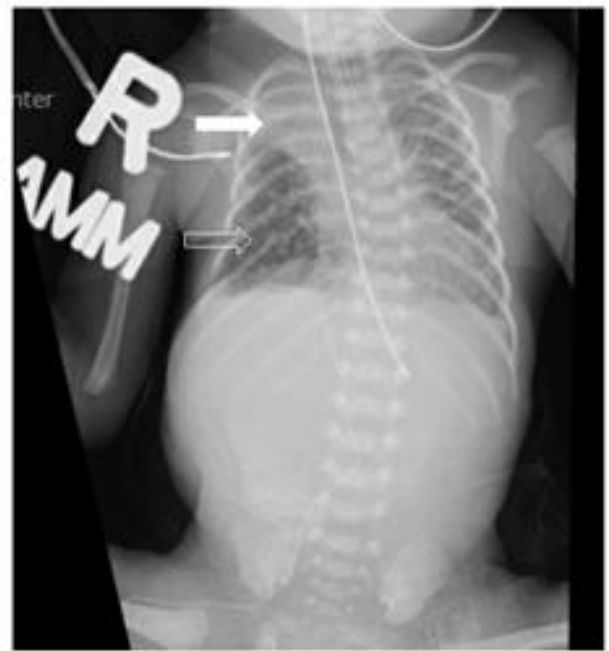

Figure 1: Chest x-ray showing right upper lobe atelectasis (bold arrow), pulmonary interstitial emphysema (open arrow)

Figure 2

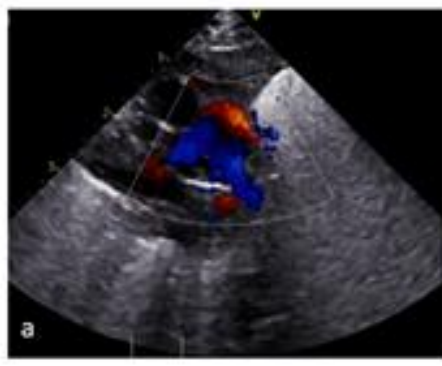

Short-axis PDA view

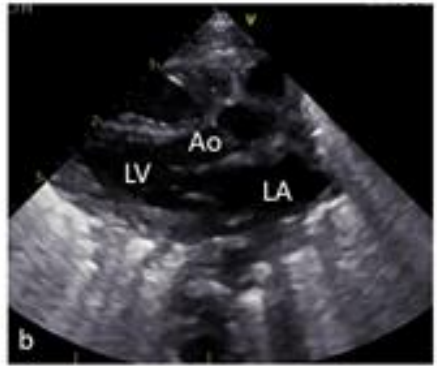

Parasternal long-axis view

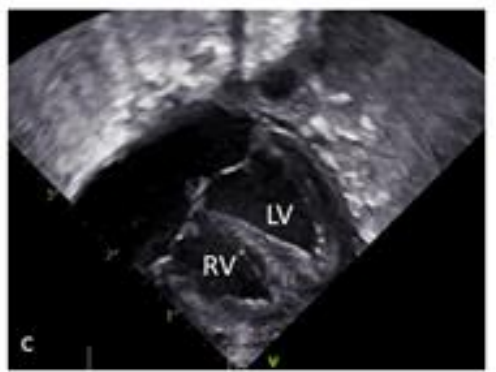

Apical-axisview

Figure 2: Echocardiogram (LA-Left Atrium, LV-Left Ventricle, Ao-Aorta, RV-Right Ventricle)

Figure 2a: Image obtained in Short-axis PDA view, showing PDA with left to right shunt

Figure 2b: Image obtained in Long-axis PDA view, showing dilated left atrium (increase LA:Ao ratio)

Figure 2c: Image obtained in apical-axis view, showing slightly low diastolic volume (ejection fraction 52\%, confirmed by M-mode measurement)

The next step should be to look for systemic signs of hypoperfusion. This infant had edematous extremities with a capillary refill time of less than two seconds. The blood gas showed a $\mathrm{pH}$ of 7.28, $\mathrm{pCO}_{2}$ of $53 \mathrm{mmHg}, \mathrm{pO}_{2}$ of $60 \mathrm{mmHg}, \mathrm{HCO}_{3}$ of $22 \mathrm{mmol} / \mathrm{Land}-0.9$ base excess. Serum creatinine was $0.7 \mathrm{mg} / \mathrm{dL}$ with normal electrolytes levels.
The fluid assessment showed an appropriate input and output (Figure 3). For persistently low blood pressure, the infant received a blood transfusion (hemoglobin of $12 \mathrm{~g} / \mathrm{dL}$ before transfusion) followed by a dopamine infusion (Figure 4). No extra fluid boluses were given. 
Figure 3

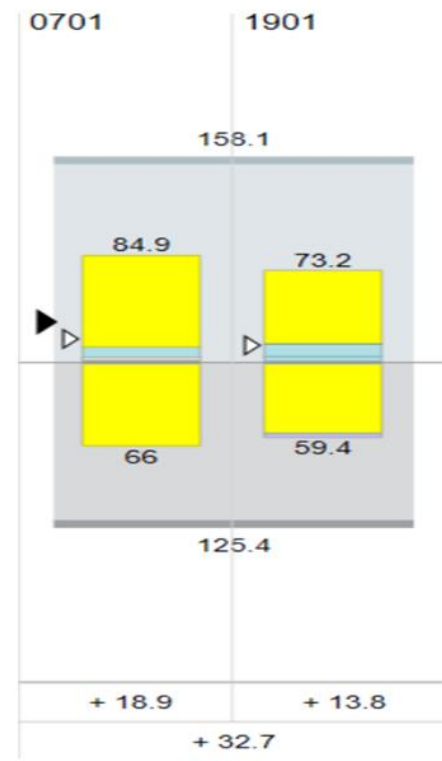

Weight 1210 grams

Total fluid intake $=158 \mathrm{ml}(130 \mathrm{~mL} / \mathrm{kg} / \mathrm{d})$

Total urine output $=125(4.3 \mathrm{~mL} / \mathrm{kg} / \mathrm{hr})$

Net positive balance $=+32.7 \mathrm{~mL}$

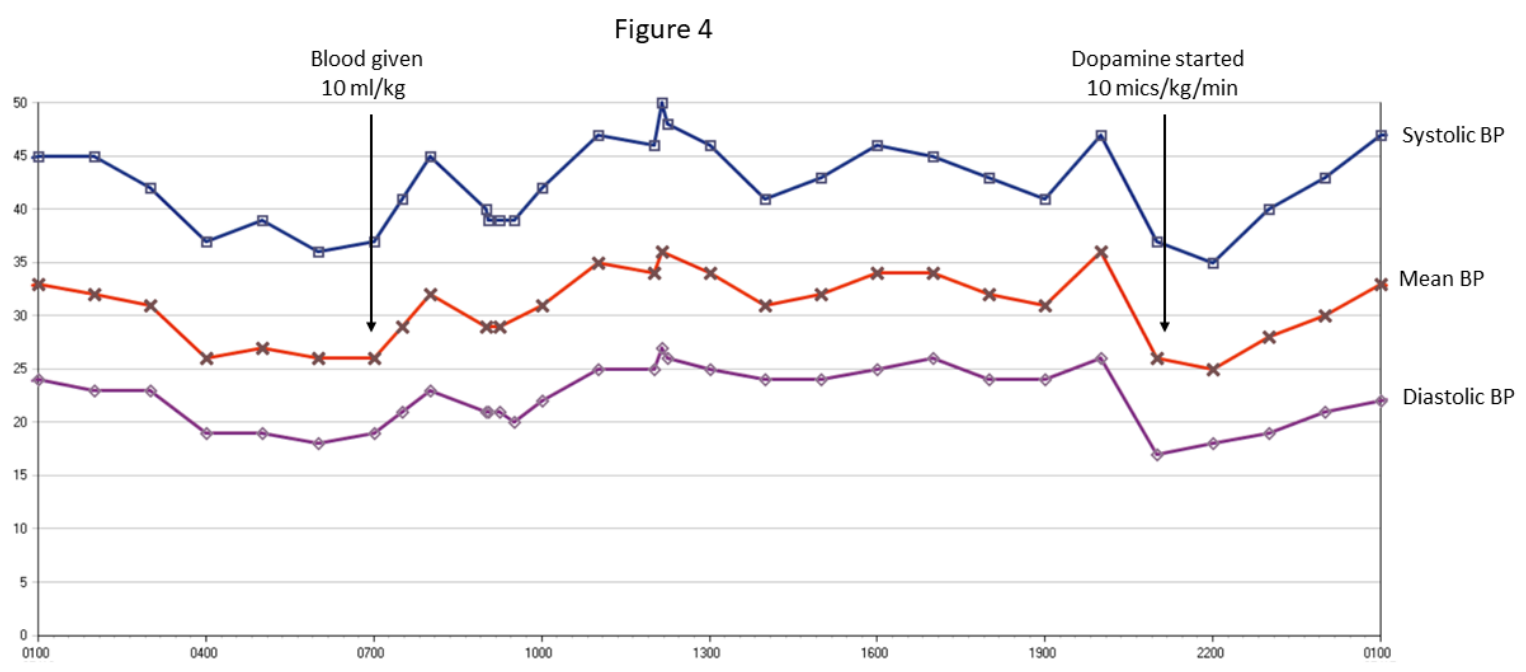

24-hour Blood Pressure Readings

Figure 4: 24-hour blood pressure readings obtained from indwelling radial artery catheter (arrows pointing at the time of use of blood and dopamine)

In every situation, a fluid bolus should not be given without a complete clinical assessment. Ewer et al [9] have concluded in their study that unless there is clear evidence of hypovolemia, clinicians should exercise caution when prescribing volume expansion.
They showed that aggressive fluid bolus administration of or greater than $30 \mathrm{~mL} / \mathrm{kg}$ is associated with increased mortality in neonates of $27-28$ weeks' gestation. 
In conclusion, when encountered with hypotension in a preterm infant with concomitant PDA, one must look at many factors to decide on the fluid chase. (Figure 5 and 6) summarize these steps. A comprehensive assessment of the respiratory status, perfusion, and urine output should be coupled with an echocardiogram, blood gases, serum creatinine, and electrolytes.

Figure 5
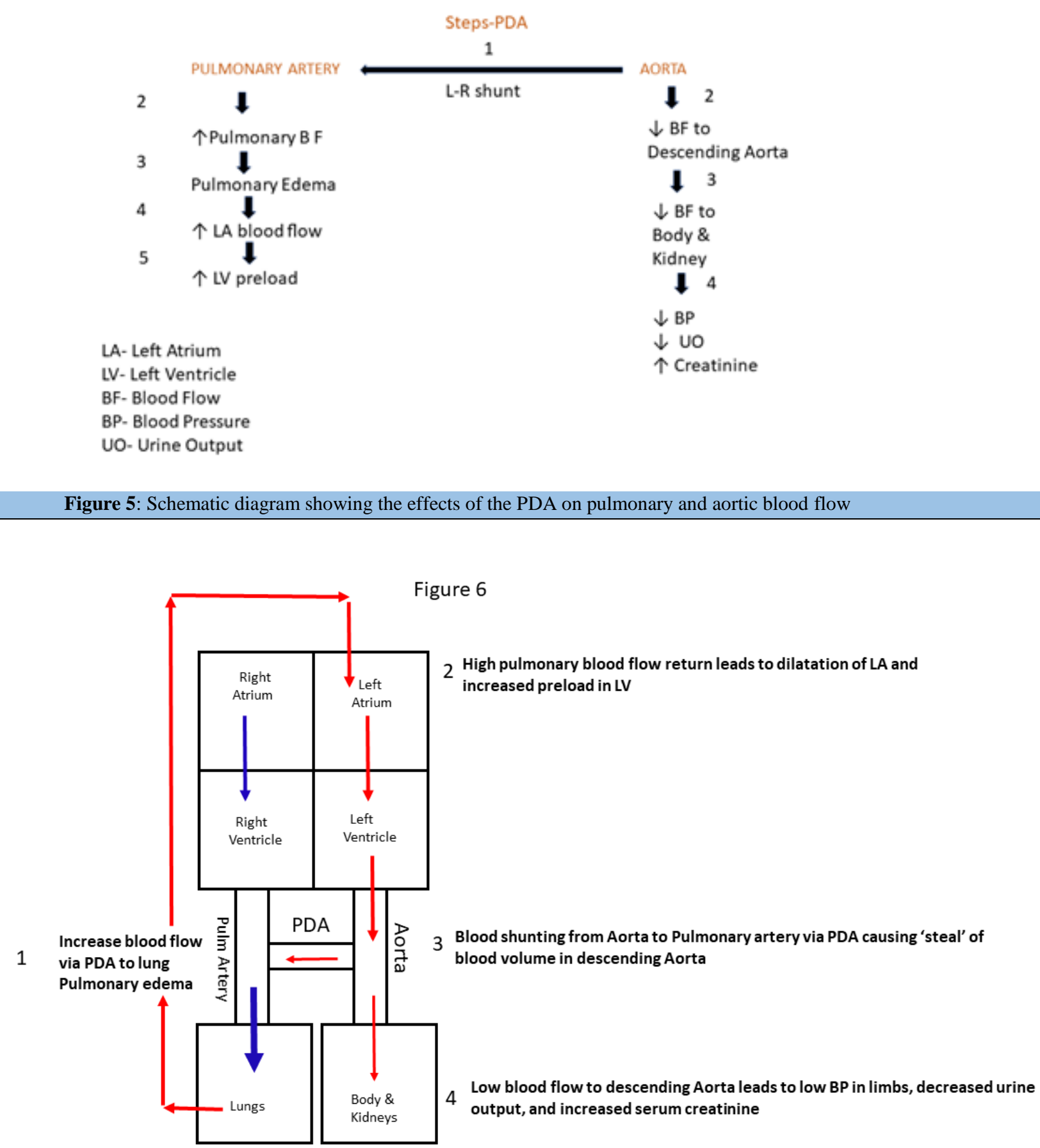


\section{Conflict of Interest: None}

Funding Source: None

\section{References:}

1. Hoffman JI, Kaplan S. (2002) The incidence of congenital heart disease. J Am Coll Cardiol 39:1890-1900.

2. Clyman RI. (2006) Mechanisms regulating the ductus arteriosus. Biol Neonate. 89:330-335

3. Investigators of the Vermont-Oxford Trials Network Database Project. The Vermont-Oxford Trials Network: very low birth weight outcomes for 1990. Pediatrics 1993; 91:540-545.

4. Noori S, McCoy M, Friedlich P, Bright B, Gottipati V, Seri I. (1993) Failure of ductus arteriosus closure is associated with increased mortality in preterm infants. Pediatrics 2009; 123:e138-144.

5. Schmidt B, Roberts RS, Fanaroff A, Davis P, Kirpalani HM, Nwaesei C, et al. (2006) Indomethacin prophylaxis, patent ductus arteriosus, and the risk of bronchopulmonary dysplasia: further analyses from the Trial of Indomethacin Prophylaxis in Preterms (TIPP). J Pediatr 148:730-734.
6. Giesinger RE, McNamara PJ. (2016) Hemodynamic instability in the critically ill neonate: an approach to cardiovascular support based on disease pathophysiology. Semin Perinatol. 40(3):174-188.

7. Batton B, Li L, Newman NS, et al. (2013) Use of antihypertensive therapies in extremely preterm infants. Pediatrics. 131: e1865

8. Gillam-Krakauer M, Reese J. (2018) Diagnosis and Management of Patent Ductus Arteriosus. Neoreviews. 19(7):e394-e402.

9. Ewer AK, Tyler W, Francis A, et al. (2003) Excessive volume expansion and neonatal death in preterm infants born at 27-28 weeks gestation. Paediatr Perinat Epidemiol. 17:180
This work is licensed under Creative Commons Attribution 4.0 License

\section{To Submit Your Article Click Here: Submit Article}

DOI:10.31579/2641-0419/074
Ready to submit your research? Choose Auctores and benefit from:

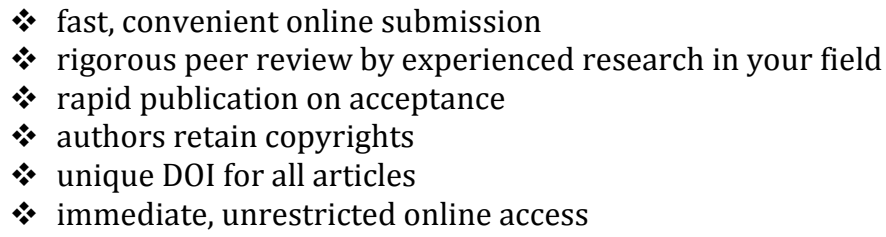

At Auctores, research is always in progress.

Learn more www.auctoresonline.org/journals/clinical-cardiology-andcardiovascular-interventions 